\title{
Designing and dimensioning of a new type of pump that can be used in the field of land reclamation
}

\author{
Mariana Mirela Stoican (Prisecaru) , ${ }^{*}$ and Nicolae Băran ${ }^{1}$ \\ ${ }^{1}$ University Politehnica of Bucharest, Faculty of Mechanical Engineering and Mechatronics, Splaiul \\ Independenței, no. 313, Bucharest, Romania
}

\begin{abstract}
The findings made during the operation of the pumping stations within the land improvement arrangements, energy balances, measurements performed and low efficiencies that are currently between $50 \%-77 \%$, it is necessary to continue research in order to improve parameters and replacement of existing aggregates with energy efficient equipment. Thus, theoretical and experimental research was performed in order to improve the projected theoretical parameters of a rotating volumetric pump. For a certain water flow rate that should be transported to irrigate an area of agricultural land or discharged from a land area equipped with drainage works, a rotating pump is dimensioned and the flow rate according to the number of rotations diagram is plotted.
\end{abstract}

\section{Introduction}

A current research direction is to improve the performance of the machines that transports fluids. Optimizing the interior architecture of working machines is a very important issue, a problem studied both in our country and abroad.

Both motor and working machines evolve over time in the following direction:

- For motor machines, the aim is to produce the maximum mechanical work yielded outside.

- For working machines, the minimum consumption of mechanical work from the outside is sought.

The architectural problem of rotors, consists in finding solutions for optimizing their geometry and the choice of parameters that lead to a more efficient fluid transport.

For rotating working machines with profiled rotors, the problem regarding the architecture of the rotor is the optimization of its geometry and the choice of parameters that lead to a more efficient fluid transport.

Minimizing the driving power of volumetric pumps with profiled rotors and finding a new architecture of the profiled rotor are key elements in the conception and designing of a new rotating machine.

\footnotetext{
* Corresponding author: mirela.prisecaru@yahoo.com
} 
Rotating pumps are included in the category of rotating working machines for liquid circulation.

In technics, there are two main criteria for pumps classification [1] [2]:

I. According to the operation principle;

II. According to the driving mode.

I. According to the operation principle, two categories are distinguished:

A. Volumetric pumps;

B. Non-volumetric pumps.

The main feature of volumetric pumps is the relative independence of the flow rate from the suction pressure values and especially at the pump discharge. For this type of hydraulic generators, the flow rate is given by the sum of the elementary volumes pumped in the unit of time.

II. There are three categories of pumps according to the driving mode [2]:

- Electro-pumps; pumps; turbopump.

Table 1 classifies the pumps according to the operating principle [3].

Table 1. Categories of pumps.

\begin{tabular}{|c|c|c|}
\hline \multirow{8}{*}{$\begin{array}{l}\text { A) Volumetric } \\
\text { pumps }\end{array}$} & \multirow{3}{*}{ Piston pumps } & a) Single cylinder pumps \\
\hline & & b) Polycylindrical pumps \\
\hline & & c) Pumps with axial pistons \\
\hline & \multirow{5}{*}{ Rotating pumps } & d) Blade pumps \\
\hline & & e) Gear pumps \\
\hline & & f) Screw pumps \\
\hline & & g) Lobe pumps \\
\hline & & h) Pumps with profiled rotors \\
\hline \multirow{2}{*}{$\begin{array}{l}\text { B) Non-volumetric } \\
\text { pumps }\end{array}$} & \multicolumn{2}{|c|}{ Centrifugal pumps } \\
\hline & \multicolumn{2}{|r|}{ Axial pumps } \\
\hline
\end{tabular}

Next, the paper will study the category of rotating volumetric pumps, namely, the one with profiled rotors $(\mathrm{h})$.

\section{The pump sketch and the operation principle}

The main dimensions of the pump, which has two identical rotors, must first be determined:

- 1 - the rotor length $[\mathrm{m}]$;

- $\mathrm{R}_{\mathrm{r}}$ - the machine rotor radius $[\mathrm{m}]$;

- $\mathrm{z}$ - the height of the rotating piston [m].

The case radius $\left(R_{c}\right)$ results from the sum of the rotor radius $\left(R_{r}\right)$ and the height of the piston (z) (figure 1).

$$
R_{c}=R_{r}+z[m]
$$

What is the connection between $\mathrm{z}$ and $\mathrm{R}_{\mathrm{r}}$ ? How big can $\mathrm{z}$ be in relation to $\mathrm{R}_{\mathrm{r}}$ ? 
To solve this problem, we will consider a single piston (5) positioned on the lower rotor (1) [4] [5].

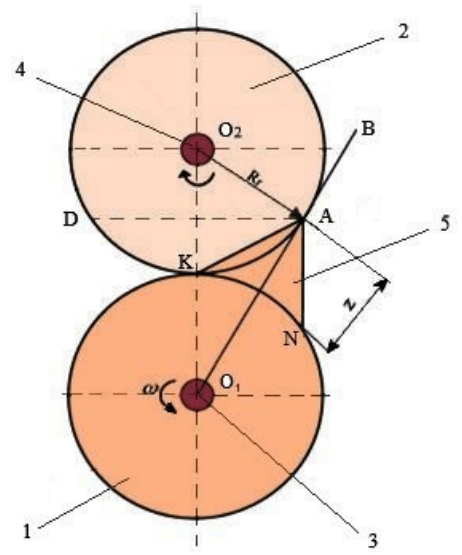

Fig. 1. Calculation notations

1 - rotor located at the bottom; 2 - rotor located at the top;

3 - the driving shaft of the machine; 4 - the driven shaft of the machine;

5 - rotating triangular piston.

The radius of the rotor (1) of the rotating machine is extended by a length ( $\mathrm{z}$ ) so that the line $\mathrm{O}_{1} \mathrm{~B}$ reaches at point $\mathrm{A}$ the rotor (2). In this way, the sealing between the two rotors is ensured by direct contact between the side surfaces of the rotors.

Analyzing the triangle $\mathrm{O}_{1} \mathrm{O}_{2} \mathrm{~A}$ will result:

$$
\begin{aligned}
& O_{1} O_{2}{ }^{2}=A O_{2}{ }^{2}+A O_{1}{ }^{2} \\
& \left(2 R_{r} z\right)^{2}=R_{r}{ }^{2}+\left(R_{r}+z\right)^{2}
\end{aligned}
$$

relations that become:

$$
z^{3}+2 R_{r} z-2 R_{r}^{2}=0
$$

If in relation (4) the derivative is performed according to the height of the rotating piston $(\mathrm{z})$ one can obtain:

$$
z=-R_{r}
$$

That is, $\mathrm{z}$ is maximum when it becomes equal to the rotor radius $\mathrm{R}_{\mathrm{r}}$; from the conditions of sealing and execution of the rotors, it is chosen $z<R_{r}$.

The rotating volumetric pump with profiled rotors consists of (figure 2) two profiled rotors $(3,7)$, which rotate at the same speed inside the cases $(1,4)$; the profiled rotors are engaged by two gears (8) mounted inside the side wall of the pump case, thus ensuring their synchronization. The shaft drives the lower rotor through a flange fixed with rotor screws; the flange rotates inside the side wall of the case (figure 2.b) [6] [7]. 


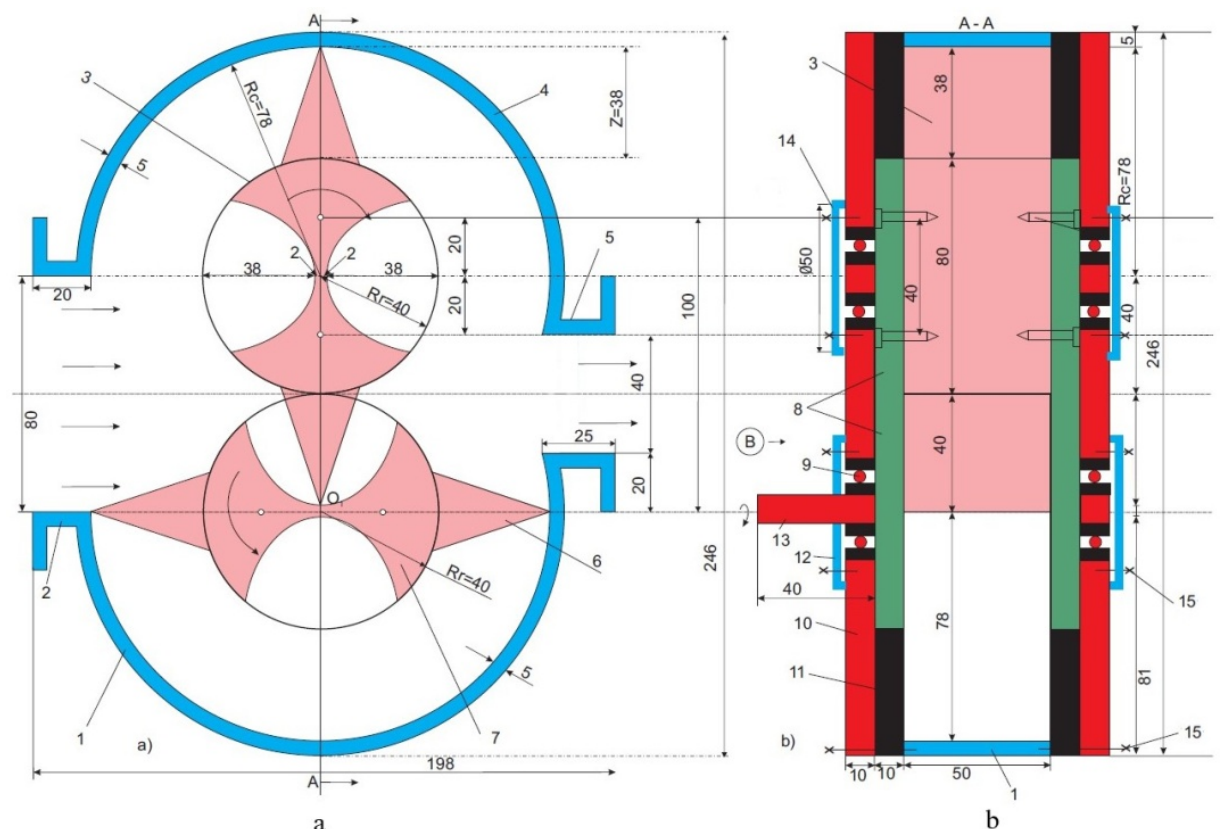

Fig. 2. Cross section (a) and longitudinal section (b) through the rotating machine a: 1 - lower case; 2 - fluid suction connection; 3 - upper rotor;

4 - upper case; 5 - fluid discharge connection; 6 - rotating piston; 7 - lower rotor; b: 8 - gears; 9 - bearings; 10 - side wall (left) of the case; 11 - intermediate wall; 12 - bearing cover; 13 - driving shaft; 14 - sealing caps; 15 - clamping screws.

The technical solution shown in figure 2 has the following characteristics:

a) The height of the piston is approximately equal to the radius of the rotor, thus increasing the useful volume of fluid conveyed;

b) The shaft for each rotor does not penetrate inside the rotor, so $\mathrm{z} \rightarrow \mathrm{R}_{\mathrm{r}}$.

For the construction of the rotors, a mathematical calculation program was elaborated, which specifies the shape of the rotor contour, and their execution was performed with the help of a numerically controlled machine tool (C.N.C.).

Figure 3 shows the location of the rotors inside the case.

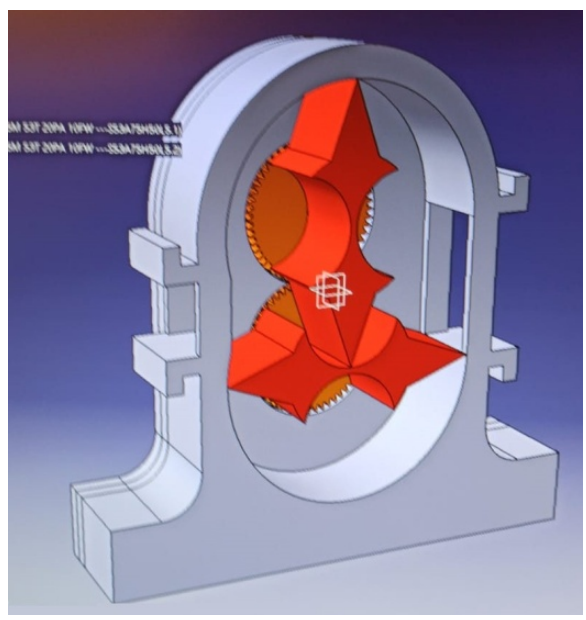


Fig. 3. Axonometric view of the case with the two rotors mounted inside it.

Figure 4 shows the operation of the rotating volumetric pump with profiled rotors. One can observe that after a $180^{\circ}$ rotation the useful volume of the transported fluid $\left(\mathrm{V}_{\mathrm{u}}\right)$ is discharged into the discharge chamber.
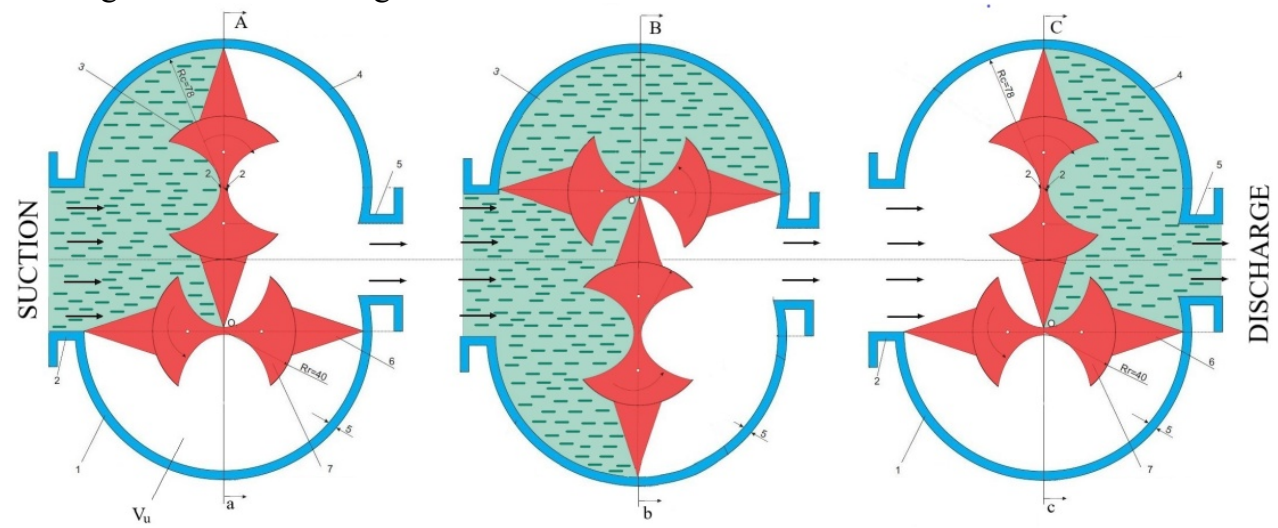

Fig. 4. Operating principle of the rotating volumetric machine

1 - lower case; 2 - fluid suction connection; 3 - upper rotor;

4 - upper case; 5 - fluid discharge connection; 6 - rotating piston; 7 - lower rotor.

The useful volume is the volume between two pistons and the case (figure 4.a).

When operating as a rotating volumetric pump with profiled rotors, two volumes $\left(\mathrm{V}_{\mathrm{u}}\right)$ will be transported from the suction to the discharge at a complete rotation of the shaft.

$$
V_{u}=2\left(\pi R_{c}^{2}+\pi R_{r}^{2}\right) l \quad\left[m^{3} / r o t\right]
$$

where: 1 - the rotor length [m].

The case radius $\left(\mathrm{R}_{\mathrm{c}}\right)$ is the sum of the rotor radius $\left(\mathrm{R}_{\mathrm{r}}\right)$ and the height of the piston $(\mathrm{z})$ :

$$
R_{c}=R_{r}+z \quad[m]
$$

The volumetric flow rate of the fluid transported by the pump will be:

$$
\dot{V}=\pi \cdot l \cdot z\left(z+2 R_{r}\right) \cdot \frac{n_{r}}{30} \quad\left[m^{3} / s\right]
$$

One can observe that the volumetric flow rate increases linearly with the length (l) and the rotor radius $\left(R_{r}\right)$ and with the speed $(n)$.

In the laboratory of the technical department of Faculty of Mechanics within the UPB, a prototype of this volumetric pump with the following characteristics was designed and built [8] [9]:

- the rotor length: $1=0.05[\mathrm{~m}]$

- the rotor radius: $\mathrm{R}_{\mathrm{r}}=0.04[\mathrm{~m}]$;

- the height of the rotating piston: $\mathrm{z}=0.038[\mathrm{~m}]$.

So, the case radius will be:

$$
R_{c}=R_{r}+z=0.04+0.038=0.078[\mathrm{~m}]
$$

An overview of the pump mounted on the test stand is shown in Figure 4. 


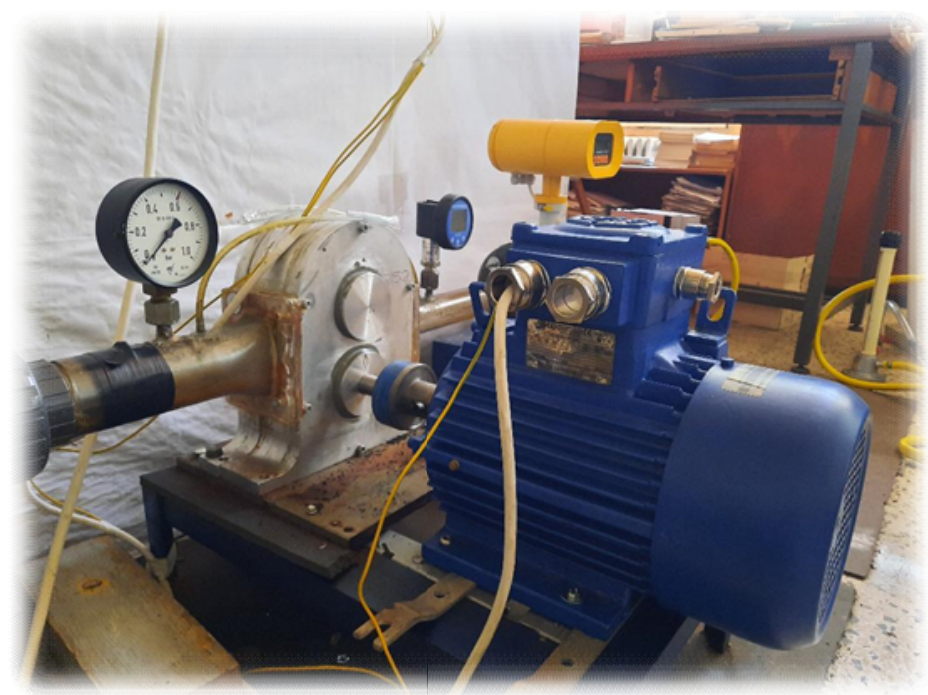

Fig. 5. Overview of the volumetric pump in the test stand.

Equation (8) is repeated, which specifies the flow rate of the pump, the rotating pistons are considered to have a triangular shape, the area of the section between the base of the prism and the rotor is neglected, and the volume of this prism will be:

$$
V_{p}=A_{\text {base }} \cdot l=\frac{1}{2} \cdot b \cdot z \cdot l=\frac{1}{2} \cdot 0.03 \cdot 0.038 \cdot 0.05 ; V_{p}=0.0285 \cdot 10^{-3} \quad\left[\mathrm{~m}^{3} / \mathrm{rot}\right]
$$

The theoretical flow rate of the machine will be lower with $\mathrm{V}_{\mathrm{p}}$.

$$
\begin{gathered}
\dot{V}_{u}=\left[\pi l z\left(z+2 R_{r}\right)-V_{p}\right] \cdot \frac{n_{r}}{30}\left[\mathrm{~m}^{3} / \mathrm{s}\right] \\
\dot{V}=\left[3.14 \cdot 0.05 \cdot 0.038(0.038+2 \cdot 0.04)-0.0285 \cdot 10^{-3}\right] \cdot \frac{500}{30} \\
\dot{V}=0.011258\left[\mathrm{~m}^{3} / \mathrm{s}\right]=40.529\left[\mathrm{~m}^{3} / \mathrm{h}\right]
\end{gathered}
$$

For the pump data presented above, choosing the operating speed of the pump as $200 \ldots$ $500[\mathrm{rpm}]$ the values in Table 2 resulted.

Table 2. The values of $\dot{V}=f\left(n_{r}\right)$.

\begin{tabular}{|c|c|c|c|c|}
\hline $\mathbf{n}_{\mathbf{r}}[\mathbf{r p m}]$ & $\mathbf{2 0 0}$ & $\mathbf{3 0 0}$ & $\mathbf{4 0 0}$ & $\mathbf{5 0 0}$ \\
\hline$\dot{V}\left[\mathrm{dm}^{3} / \mathrm{min}\right]$ & 270.18 & 405.3 & 540.42 & 675.48 \\
\hline$\dot{V}\left[\mathrm{~m}^{3} / \mathrm{h}\right]$ & 16.211 & 24.317 & 32.423 & 40.529 \\
\hline
\end{tabular}

Based on the theoretical data in Table 2 and following the experimental researches, the graph of the function $\dot{V}=f\left(n_{r}\right)$ was drawn in Figure 6 . 


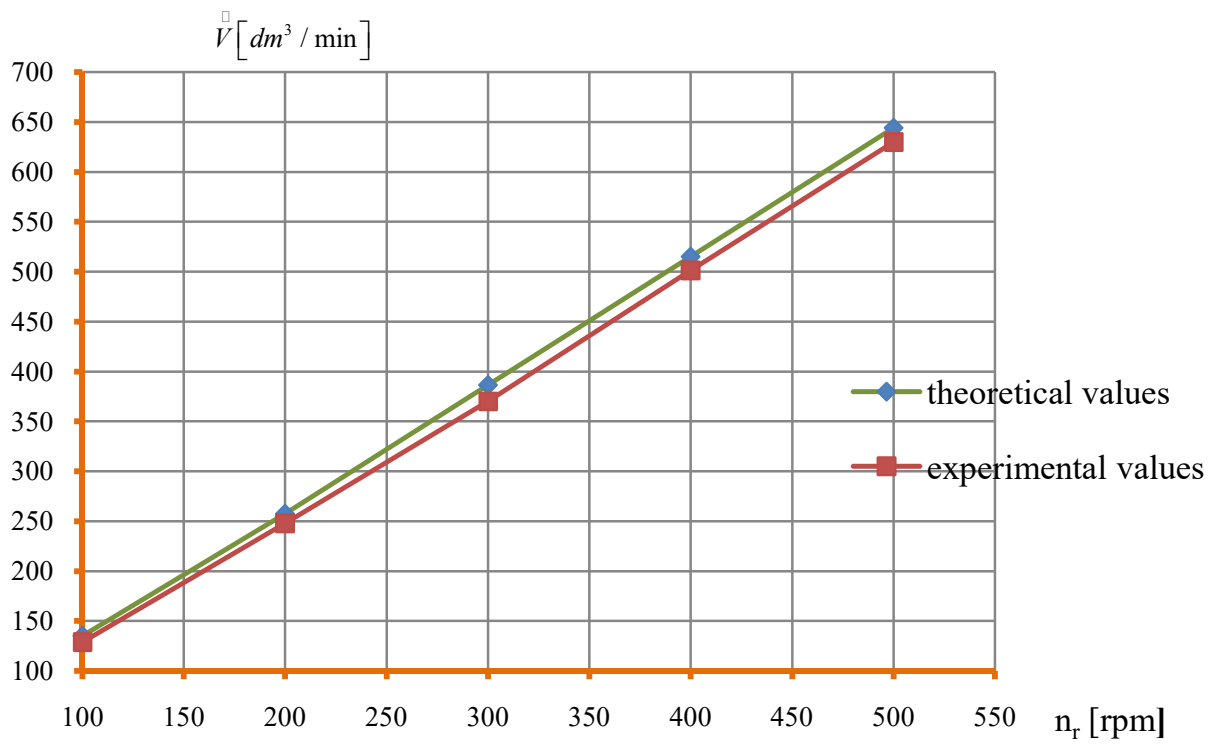

Fig. 6. The graphs of the function $\dot{V}=f\left(n_{r}\right)$

1 - theoretical values; 2 - experimental values.

Figure 6 shows that the two graphs are very close; as a result, the volumetric efficiency will be [10]:

$$
\eta_{v}=\frac{\dot{V}_{t}}{\dot{V}_{r}}
$$

Approximately, as the average value, it will be $\eta_{v}=0.95$.

\section{The use of the constructive solution of the rotating volumetric pump in the field of land reclamation}

If the characteristic sizes of the laboratory prototype are multiplied by 10 , one can obtain:

- the rotor length: $1=0.5[\mathrm{~m}]$;

- the rotor radius: $\mathrm{R}_{\mathrm{r}}=0.4[\mathrm{~m}]$;

- the height of the rotating piston: $\mathrm{z}=0.38[\mathrm{~m}]$.

The case radius will be:

$$
R_{c}=R_{r}+z=0,4+0,38=0,78[\mathrm{~m}]
$$

Substituting these values in relation (11), for different speeds $200 \ldots 500$ [rpm] the data in table 3 are obtained.

Table 3. The values of $\dot{V}=f\left(n_{r}\right)$.

\begin{tabular}{|c|c|c|c|c|}
\hline $\mathbf{n}_{\mathbf{r}}[\mathbf{r p m}]$ & $\mathbf{2 0 0}$ & $\mathbf{3 0 0}$ & $\mathbf{4 0 0}$ & $\mathbf{5 0 0}$ \\
\hline$\dot{V}\left[\mathrm{~m}^{3} / \mathrm{h}\right]$ & 16211.712 & 24317.568 & 33790.056 & 40529.280 \\
\hline
\end{tabular}




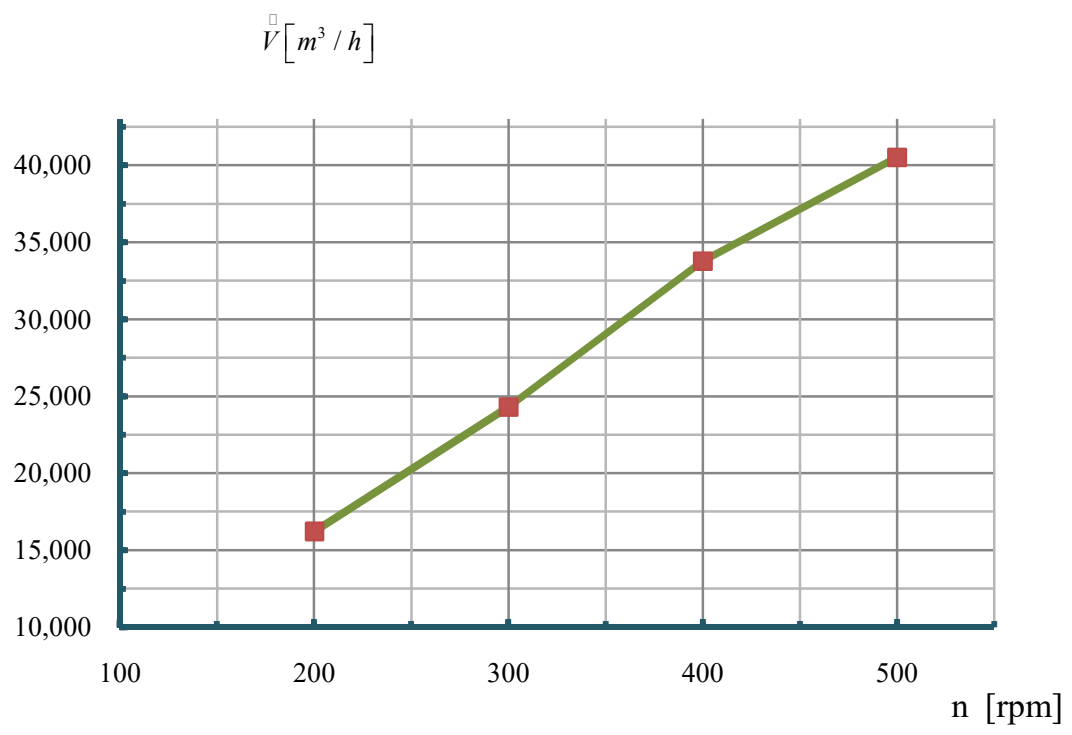

Fig. 7. The graphs of the function $\dot{V}=f\left(n_{r}\right)$

This flow rate for $n_{r}=400$ [rpm] can ensure the irrigation of 28 hectares of agricultural land, once a day with $101 / \mathrm{m}^{2}$.

\section{Conclusion}

a. Rotating working machines have the advantage of converting the motor torque received from the shaft into potential pressure energy with minimal losses.

b. The advantages of this original construction solution is that it can transport high flows rate water with lower energy consumption compared to existing pumps in irrigation stations.

c. As a result of the theoretical and experimental research carried out in the laboratory, the effective efficiency of the machine of $78 \%$ resulted. The actual efficiency of the machine is influenced by the nature of the fluid transported by the viscosity and of the machine speed.

d. Thus, we conclude that the driving power is influenced by the flow rate (i.e., by the parameters mentioned above) by the increase in pressure $(\Delta p)$ achieved by the rotating machine between suction and discharge, the nature of the transported fluid.

e. Volumetric pump with profiled rotors can be used in the field of land reclamation, in wastewater treatment plants, in: mining, energy, petrochemical industry.

f. There is a good concordance between theoretical data and those experimentally determined.

\section{References}

1. N. Băran, P. Răducanu, a.o., Bases of Technical Thermodynamics, Technical Thermodynamics (in Romanian), POLITEHNICA PRESS Publishing House, Bucharest (2010).

2. C. Țurcanu, N. Ganea, Volumetric Pumps for Liquids, (in Romanian), Technical Publishing House, Bucharest (1980). 
3. M. Exarhu, Pneumatic and hydraulic machine and installations, (in Romanian), SC. ANDOR SRL, Bucharest, 2011.

4. N. Băran, A. Detzortzis, M. Hawas, D. Besnea, The correlation between the rotor shape and the energetic performance of a rotating machine with profile rotors, The Romanian Review Precision Mechanics, Optics \& Mechatronics, no. 45,18-26 (2014).

5. M. Hawas, N. Băran, A. Detzortzis, Influence of the rotor architecture and of the speed on the volumetric efficiency of a new type of rotating volumetric machine, Advanced Materials Research, Trans Tech Publications, Switzerland, 905, 487-491, (2014).

6. M. Hawas, The influence of fluid viscosity on the performance of rotating machine with profiled rotors, $\mathrm{PhD}$ Thesis, Faculty of Mechanical Engineering and Mechatronics, University Politehnica of Bucharest (2015).

7. A. Motorga, Influence of constructive and functional parameters on the performances of rotating machines with profiled rotors, $\mathrm{PhD}$ Thesis, Faculty of Mechanical Engineering and Mechatronics, University Politehnica of Bucharest (2011).

8. N. Băran a.o., Bases of Technical Thermodynamics, (in Romanian), POLITEHNICA PRESS Publishing House, Bucharest, 3 (2010).

9. N. Băran, A. Motorga, D. Duminică, Research Regarding the Building of an Experimental Setup for the Testing of a New Type of Rotating Machine with Profiles Rotors, Mechatronics Magazine, no.1, 27-30, (2011).

10. N. Băran, D. Besnea, A. Motorga, Elements of computing the architecture and manufacturing technology for a new type of profiled rotor, Proceedings International Conference, 6th Workshop on European Scientific and Industrial Collaboration on promoting Advanced Technologies in Manufacturing, WESIC'08, Bucharest, 233-241 (2008). 